\title{
Study on Aerodynamic Performance of Offshore Wind Turbine with Floating Platform Motion
}

\author{
X.M. Ding \\ Institute of Ocean Renewable Energy System \\ Harbin Engineering University \\ Heilongjiang, China
}

\author{
L. Zhang \\ Institute of Ocean Renewable Energy System \\ Harbin Engineering University \\ Heilongjiang, China
}

\author{
Y. Ma \\ Institute of Ocean Renewable Energy System \\ Harbin Engineering University \\ Heilongjiang, China
}

\begin{abstract}
In order to study the effect of the floating platform motion on the aerodynamic performance of offshore wind turbine, this paper analyzes the aerodynamic performance under different amplitudes of tossing movements on unsteady Blade Element Momentum Theory (BEM).The numerical model for aerodynamic performance of floating wind turbine under control system is established, which is based on the model of 5MW offshore wind turbine of National Renewable Energy Laboratory (NREL). Due to the limitation of the unsteady Blade Element Momentum Theory itself, the dynamic wake model and the yawing correction are added into the unsteady BEM theory with the Prandtl blade tip and hub loss correction, the Glauert correction and three-dimensional rotation correction. The change of thrust, torque and power in six degrees of freedom are received by calculation and the laws about aerodynamic performance of the offshore wind turbine under the six degrees of freedom platform motion is summarized.
\end{abstract}

Keywords-BEM;offshore wind turbine;NREL

\section{INTRODUCTION}

The bottom of ordinary stationary wind turbine is fixed with the ground rigidly. The external force from the bottom can make tower produce the structural issues such as yield and fatigue, but it will not affect the aerodynamic performance of the wind turbine. The Floating Offshore Wind Turbine (FOWT) in complex sea environment, based mainly on mooring chain. Under the action of the wind, wave and flow, the wind turbine will produce six degrees of freedom movement such as yaw, tilt, which affects the relative wind speed of wind turbine and the aerodynamic performance of the Floating Offshore Wind Turbine.

In this paper, the National Renewable Energy Laboratory (NREL)-5mw horizontal axis three blade variable speed variable pitch offshore wind turbine is used for the prototype of theory and the theory of unsteady BEM [1-2] is calculated based on revised theory. Six degrees of freedom movement producing by floating foundation influences the inflow velocity of wind turbine respectively with the main control system. It provides references for complex nonlinear coupling problem.

\section{CORRection of Blade Element Momentum THEORY}

Because of the complex vortex system structure of the wind turbine [3-4], simplifying the wake flow structure and for the hypothesis which the number of rotor blades is boundless, Prandtl blade tip and hub loss correction is used. Define induced velocity correction factor of blade tip as $F_{1}$.

$$
\begin{aligned}
F_{1} & =\frac{2}{\pi} \arccos e^{-f_{1}} \\
f_{1} & =\frac{B}{2} \frac{R-r}{r \sin \phi}
\end{aligned}
$$

In equation: $B$ is the blade number of wind turbine; $R$ is the whole radius of wind turbine; $r$ is the local radius of wind turbine; $\phi$ is the inflow Angle.

Analogizing blade tip, define induced velocity correction factor of hub as $F_{2}$.

$$
\begin{aligned}
F_{2} & =\frac{2}{\pi} \arccos e^{-f_{2}} \\
f_{2} & =\frac{B}{2} \frac{r-R_{h u b}}{r \sin \phi}
\end{aligned}
$$

In conclusion, define Prandtl blade tip and hub loss correction factor as $F$

$$
F=F_{1} \cdot F_{2}
$$

When the axial induced factor $a_{\mathrm{n}}$ more than 0.4 , the accuracy of data is low because of the simple theorem of momentum. The Glauert correction is used based on local aerodynamic. Define the axial induced factor as $a_{\mathrm{n}}$ 


$$
a_{n}=\left\{\begin{array}{cc}
\frac{1}{\frac{4 F \sin ^{2} \phi}{\sigma C_{n}}+1} & a_{n} \leq a_{c}(6) \\
\frac{1}{2}\left\{2+k\left(1-2 a_{c}\right)-\sqrt{\left.\left[\left(k\left(1-2 a_{c}\right)+2\right)^{2}+4\left(k a_{c}^{2}-1\right)\right]\right\}}\right. & a_{n}>a_{c} \\
k & =\frac{4 F \sin ^{2} \phi}{\sigma C_{n}}
\end{array}\right.
$$

In equation: $C_{\mathrm{n}}$ is normal load coefficient; $\sigma$ is solidity; $a_{\mathrm{c}}$ is axial induced velocity factor at critical time, about 0.2 .

Due to the lift force and drag force coefficient of wind turbine acquired by wind the tunnel experiment of twodimensional airfoil, the blade unit is regarded as twodimensional airfoil. In the program separation factor model is used to calculate the Blade Element Momentum Theory. $\Delta C_{1}$ is increment of lift coefficient; $\Delta C_{\mathrm{d}}$ is reduction of drag coefficient, so define the corresponding three-dimensional lift and drag coefficient as $\mathrm{C}_{\mathrm{l}, 3 \mathrm{~d}}$ and $\mathrm{C}_{\mathrm{d}, 3 \mathrm{~d}}$.

$$
\begin{gathered}
C_{l, 3 D}=C_{l, 2 D}+\Delta C_{l} \\
C_{d, 3 D}=C_{d, 2 D}-\Delta C_{d}
\end{gathered}
$$

In equation: $\mathrm{C}_{1,2 \mathrm{~d}}$ and $\mathrm{C}_{\mathrm{d}, 2 \mathrm{~d}}$ is two-dimensional lift and drag coefficient [5-8].

\section{PERFORMANCE OF OFFSHORE WIND TURBINE WITH FLOATING PLATFORM MOTION}

Conceptual model parameters of the projects such as WindPACT, RECOFF and DOWEC are referenced. Integrated NREL $5 \mathrm{MW}$ wind turbine main parameters are as follows:diameter of wind turbine is $126 \mathrm{~m}$; hub height from sea level is $90 \mathrm{~m}$; cut-inwindspeed, ratedwindspeed and cut-out windspeed are $3.0 \mathrm{~m} / \mathrm{s}, 11.4 \mathrm{~m} / \mathrm{s}$ and $25 \mathrm{~m} / \mathrm{s}$; coneangle, tilt angle of main shaft, initial yaw angle and initial pitch angle are $0^{\circ}$.

\section{A. The Platform Motion}

Under the action of the wind, wave and flow, the floating foundation of wind turbine will produce six degrees of freedom movement, such as yaw, pitch, roll, surge, sway, heave. This paper usesthe angle of yaw, pitch, roll $\beta_{\text {yaw }}, \beta_{\text {pitch, }}, \beta_{\text {roll }}$ and the displacement of surge, sway, heave $S_{\text {surge }}, S_{\text {sway }}, S_{\text {heave }}$ to describe the motion.

In the study of six degrees of freedom movement, the wind speed is assumed as $11.2 \mathrm{~m} / \mathrm{s}$ less than rated wind speed 11.4 $\mathrm{m} / \mathrm{s}$; the rated rotate speed of wind turbine is $12.1 \mathrm{rpm}$.Six kinds of motion are sinusoidal movement:

$$
\gamma=\gamma_{A} \sin \omega t
$$

In order to obtain the aerodynamic performances when the wind turbine runs smoothly,thedata after 400 s are selected in the following graphs to be studied. The thrust, torque and power of oscillation period are studied based on the sinusoidal motion condition of floating foundation. Circular frequency is elected as $\omega=0.1 \pi \mathrm{rad} / \mathrm{s}$ based on Offshore Floating Wind Turbine Design Standard from DNV. It conforms to typical wave period 5-25s in China. The amplitudesof angle motion with floating foundationare $6^{\circ}, 8^{\circ}, 10^{\circ}$, and amplitudesof linear motion are $6 \mathrm{~m}, 8 \mathrm{~m}, 10 \mathrm{~m}$.

In actual cases, the wind turbine control system will affect the change of the aerodynamic performance.Assume that wind turbine speed measuring device can only be induced horizontal inflow velocity, so the control system will not affect its aerodynamic performance specially for movement can't change the horizontal inflow such as yaw and heave.

\section{B. Aerodynamic Performance of Wind Turbine with Angle Motion of Floating Foundation}

This paper only gives the aerodynamic performance changing with six degrees of freedom movement in a cycle of $20 \mathrm{~s}$. When the cycle is not same, the overall trend of aerodynamic performances' change is similar in each degree of freedom movement. When the inflow velocity of hub is convection, thrust, torque and power are $597.40 \mathrm{kN}, 4256.67 \mathrm{kN} \bullet \mathrm{m}, 5393.67 \mathrm{~kW}$.
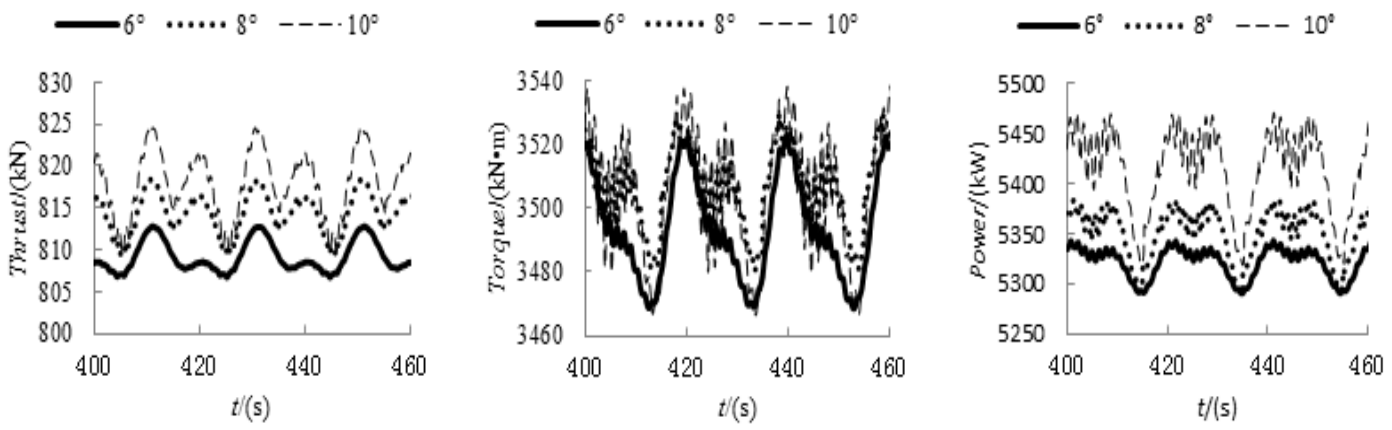

(a)Thrust(b)Torque

(c)Power

FIGURE I. AERODYNAMIC PERFORMANCE IN YAW. 
That can be seen from Figure 1, the average and amplitude of thrust; amplitude of torque and the average and amplitude of power increase when the angle of yaw increases, but the change is small. Due to the large rotor diameter, slight yaw will affect the inflow velocity of wind turbine to be uniform.
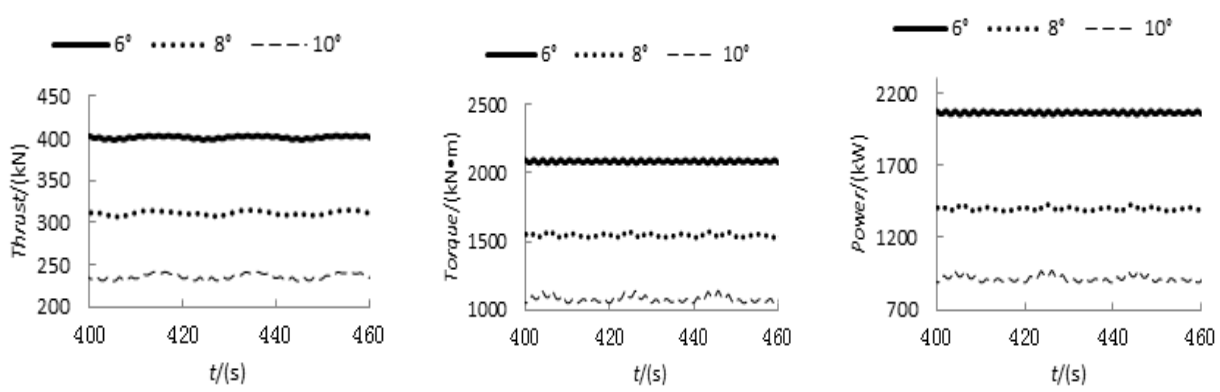

(a)Thrust(b)Torque

(c)Power

FIGURE II. AERODYNAMIC PERFORMANCE IN PITCH.

That can be seen from Figure 2, the average thrust; the average torque and the average power decrease when the angle of pitch increases. The amplitude of thrust; the amplitude of torque and the amplitude of power increase when the angle of pitch increases. The wind turbine's pitch is similar to yaw, because both of them don't change the inflow velocity of hub. But it will affect the tilt angle of wind turbine.
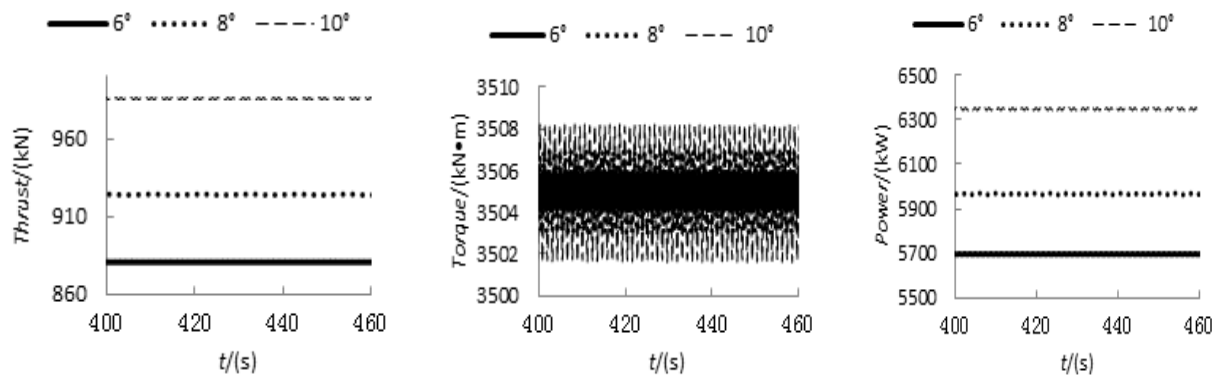

(a)Thrust(b)Torque

(c)Power

FIGURE III. AERODYNAMIC PERFORMANCE IN ROLL.

That can be seen from Figure 3, the average power decrease when the angle of roll increases. The average and amplitude of thrust; the amplitude of torque and the amplitude of power increase when the angle of roll increases. The average torque almost doesn't change. Because of the height of tower, a small roll can cause a greater change of inflow velocity. Roll occurs when wind and wave are in different directions, and can lead to inflow velocity increases. But the control system of wind turbine can be adjusted by the pitch angle to maintain the rotate speed of wind turbine staying at a rated rotate speed.

\section{Aerodynamic Performance of Wind Turbine with Linear Motion of Floating Foundation}
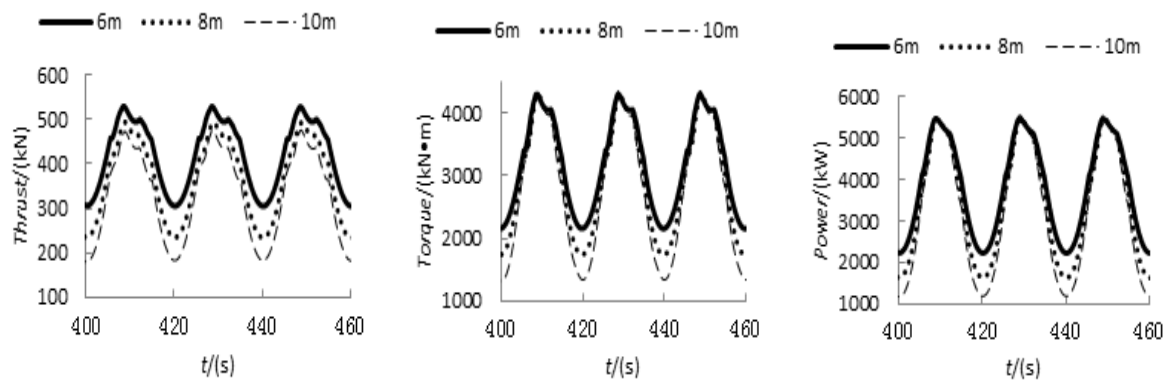

(a)Thrust(b)Torque

(c)Power

FIGURE IV. AERODYNAMIC PERFORMANCE IN SURGE. 
That can be seen from Figure 4, the average thrust; the average torque and the average power decrease when the distance of surge increases. The amplitude of thrust; the amplitude of torque and the amplitude of power increase when the distance of surge increases. The huge pneumatic thrust of upper wind turbine will generate larger surge movement when it works. Different from pitch, surge only changes the inflow velocity of hub not the tilt angle.
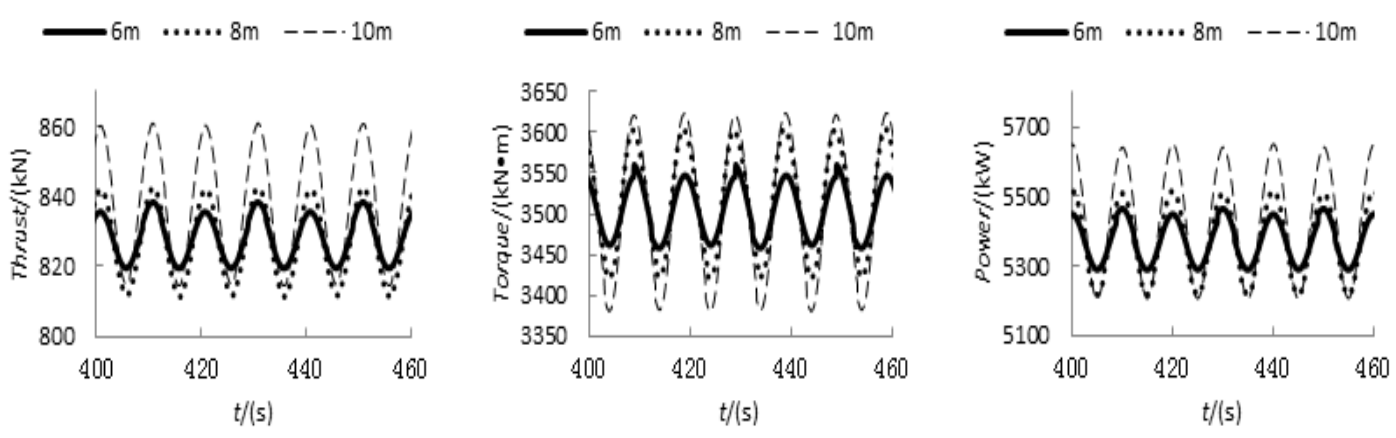

(a)Thrust(b)Torque (c)Power

FIGURE V. AERODYNAMIC PERFORMANCE IN SURGE.

That can be seen from Figure 5, the amplitude of thrust and the amplitude of power increase when the distance of sway increases. Sway occurs when wind and wave are in different directions, and it makes wind turbine always yaw. Sway changes horizontal wind speed and influence yaw angle of wind turbine at the same time, so the inflow velocity of hub will increase. When the speed no longer yaws, namely the inflow velocity of hub is the right convection, and wind speed reaches minimum value at this time. After that wind turbine will yaw, and the wind speed will change too. Compared with the roll, sway belongs to the linear movement and it can't change the rotate speed.

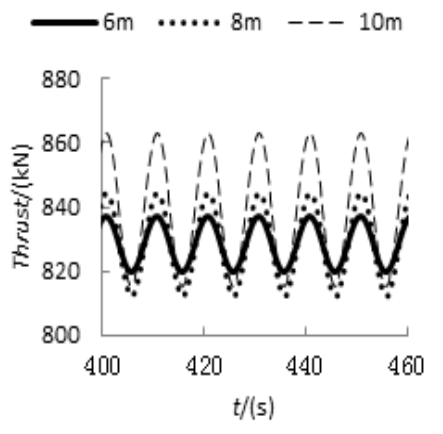

(a)Thrust(b)Torque
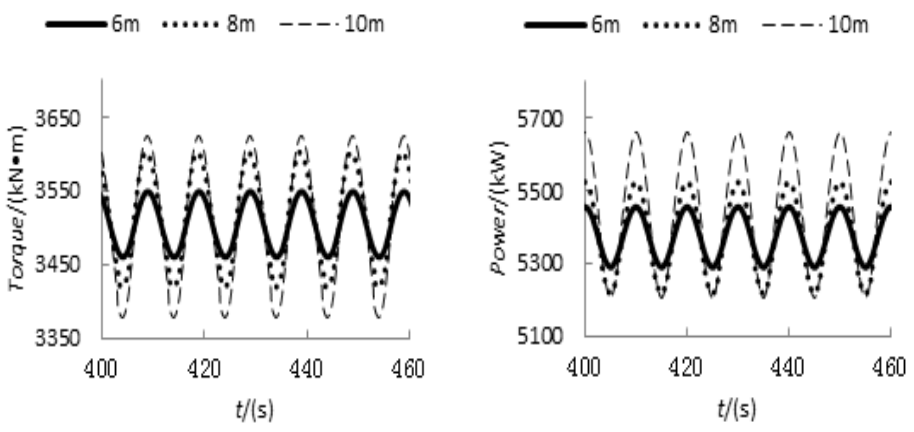

(c)Power

FIGURE VI. AERODYNAMIC PERFORMANCE IN HEAVE.

That can be seen from Figure 6, the amplitude of thrust and the average and amplitude of power increase when the distance of sway increases. Heave and sway are same, they change horizontal wind speed and the yawing state of wind turbine. However, sway affects yaw angle and heave affects pitch angle. In the case of the surge, problem of the blade stall should be paid special attention to.

\section{REFERENCES}

[1] Moriarty P. J. \& Colorado G., 2005, AeroDyn Theory Manual. National Renewable Energy Laboratory, pp.2-3.

[2] Leishman J. G. \& Beddoes T. S., 1989, A Semi-Empirical Model for Dynamic Stall. Journal of the American Helicopter Society, Vol.34, NO.3, pp.3-17.
[3] Glauert, H., 1935, Airplane Propellers form Aerodynamic Theory, Vol. 4, Division L edited by Durand W. F. , Julius Springer, pp.169-360.

[4] Chaviaropoulos, P. K. \& Hansen, M. O. L., 2000, Investigating Threedimensional and Rotational Effects on Wind Turbine Blades by Means of a Quasi-3D Navier-Stokes Slover. Journal of Fluids Engineering, Vol. 122, pp.330-3336.

[5] Hansen M. O. L., 2008, Aerodynamics of Wind Turbines, Second Edition, Earthscan: UK and USA, pp.85-102.

[6] Glauert H., 1926, A General Theory of the Autogyro. ARCR R\&M NO.1111, pp.1-6.

[7] Spera D. A., 1994, Wind Turbine Technology, First Edition, ASME Press: New York, pp.55-61.

[8] Øye. S., 1991, Dynamic stall, simulated as a time lag of separation. Proceedings of the 4th IEA Symposium on the Aerodynamics of Wind Turbines, Harwell Laboratory, Harwell, UK, pp.1-6. 